\title{
Two years of FES training improves muscle fibers of thigh muscles in long-term thoracic level-complete spinal cord injury
}

\author{
Hofer $\mathrm{C}^{1}$, Loefler $\mathrm{S}^{1}$, Kern $\mathrm{H}^{2,3}$, Zampieri $\mathrm{S}^{2,4}$, Albertin $\mathrm{G}^{5}$ and Carraro $\mathrm{U}^{4,6 *}$ \\ ${ }^{1}$ Ludwig Boltzmann Institute of electrical stimulation and physical rehabilitation, A-1160 Wien, Austria \\ ${ }^{2}$ Physiko- und Rheumatherapie, A-3100 St. Poelten, Austria \\ ${ }^{3}$ Department of Physical Medicine and Rehabilitation, Wilhelminenspital, A-1160 Wien, Austria \\ ${ }^{4}$ Department of Biomedical Science, Interdepartmental Research Centre of Myology, University of Padova, I-35131 Padova, Italy \\ ${ }^{5}$ Department of Neurosciences, Section of Human Anatomy, University of Padova, I-35100 Padova, Italy \\ ${ }^{6} \mathrm{~A} \& \mathrm{C}$ M-C Foundation for Translational Myology, I-35137 Padova, Italy
}

\begin{abstract}
To investigate the structural relationships and the progression of functional electrical stimulation (FES)-induced regression of muscle atrophy up to 20 years of spastic paraplegia, clinical follow-up and muscle biopsies were performed in Vienna, Austria. Tissue composition and fiber morphology were analyzed by light microscopy in Padua, Italy. Histology confirms that: 1 . the difference in average size of muscle fibers between mid-term ( 2 to 5 years) and long-term ( 5 to 20 years) paralyzed leg muscles is actually very small; 2 . They maintain the striated appearance characteristic of normal skeletal muscle fibers even after 20 years of paralysis; 3 . SDH histochemistry, a marker of mitochondrial content of muscle fibers, shows a dramatic decrease that is more pronounced in long-term paralyzed leg muscles. 4 . Myosin ATPase histochemistry demonstrates that there is a progressive relative increase of the fast-glycolytic muscle fibers at the expenses of the oxidative muscle fibers. Together with our previous evidence of ultrastructural alterations of the activating and metabolic machineries and of the presence of muscle fibers with lower motor neuron denervation characteristics, these features explain the low-force output and the reduced endurance of paretic muscles; 5. After two-year of FES-training the deterioration process is reversed, taking the fast muscle fibers to almost normal size values for sedentary adults. The stable muscle atrophy that characterizes longlasting spastic paraplegia and the evidence that extent of FES-training recovery does not correlate with time from SCI strongly suggest that there are no upper-time limits to begin a FES training program.
\end{abstract}

\section{Introduction}

There is numerous long-term spinal cord injury (SCI) patients (from 10 to 20 years of SCI) who could benefit from Functional Electrical Stimulation (FES) treatments, but information on their muscle conditions was scarce [1-3], before we reported on the extent of muscle atrophy in long-term thoracic-level upper motor neuron (UMN) paraplegia [4]. The many reports published have mostly studied muscle properties up to 3-5 years post-SCI [5]. Indeed, after the first few months, in which muscle mass decreases significantly, [6-8] muscle atrophy reaches a steady state. Within the first month, the thickness of the muscle bulk, measured by ultrasound, decreases up to $40 \%[8,9]$. We will indicate the period up to 3 months post SCI as the "early phase" of paraplegic atrophy. Afterwards, a 50\% stable atrophy in spastic incomplete or complete paralysis is well documented up to 2 years after SCI [9-14]. This time span (from 1.6 to 3.0 years) in the present paper is referred to as the "mid-term" phase (MT). Information on the following periods, in particular, up to 20 years post-SCI, as in our 'long-term" (LT) group, remain quite poor $[5,15]$. For this reason, we decided twelve years ago to compare by functional and structural analyses, the muscles of SCI patients affected by either MT or LT complete UMN paraplegia. We reported that mid-term (2 years after $\mathrm{SCI}$ ) and long-term (up to 20 years after injury) UMN injured muscle does not undergo the degenerative processes (muscle fiber substitution with adipose and fibrotic tissue) that devastate the muscles of 3-year lower motor neuron denervated subjects [16,17]. In UMN (spastic) paraplegia, human muscles seemed to reach and sustain a stable atrophy [4]. Histopathology confirmed that the difference in average size of muscle fibers between long-term and mid-term paralyzed leg muscles was actually progressing, but very small. We add here more information on fiber type composition/transformation of quadriceps $\mathrm{m}$. in longterm UMN-complete thoracic paraplegia by histochemical approaches and on the trophic effects observed after 2 years of FES training.

*Correspondence to: Ugo Carraro, Department of Biomedical Science, Interdepartmental Research Centre of Myology, University of Padova, Padova, Italy; E-mail: ugo.carraro@unipd.it

Special Issue: Assisted Exercise

Ugo Carraro

Interdepartmental Center of Myology

University of Padova

Italy

Paolo Gargiulo

Inst. f. Biomed. and Neural

Engineering / Biomed Technology Centre

Reykjavik University \& Landspitali Reykjavik

Iceland

Received: May 08, 2018; Accepted: May 14, 2018; Published: May 17, 2018 


\section{Materials and methods}

\section{Patients}

The study enrolled fifteen subjects who had experienced traumatic SCI affecting the upper motor neuron (from T4 to T12). Eight of them finished the study. All subjects enrolled in the project were volunteers, who had received detailed information and had signed an informed consent.

We certify that all applicable regulations concerning the ethical use of human volunteers were followed during the course of this research. (Approval: EK-03-035-0403).

Biopsies were obtained as pre-FES sampling from patients who were going to undergo a 2-year FES treatment. Patients were divided into two groups: a mid-term group composed of six patients paralyzed from two to up five years and a long-term group formed by four patients paralyzed from six up to twenty years. All subjects were classified as ASIA A. Age, sex, body weight, height, etiology and level of SCI are reported in Kern et al. 2008 [4]. Clinical and functional assessments, muscle biopsies as well as follow-up were performed at the Institute of Physical Medicine and Rehabilitation, Wilhelminenspital, Vienna, (Austria), while light microscopy of bioptic specimens at the Department of Biomedical Science, University of Padova, Italy.

\section{Muscle biopsies}

Through a small skin incision $(6 \mathrm{~mm}$ in diameter), needle muscle biopsies were taken from the right and left vastus lateralis muscles before start and after 2 years of FES training for each patient, as described by Kern et al. 2004 [16]. The resulting specimens were then prepared either for light and/or electron microscopy.

\section{Histochemistry}

Fibre typing by succinate dehydrogenase (SDH) reaction: $\mathrm{SDH}$ staining was performed to distinguish between oxidative and nonoxidative (or "less" oxidative) muscle fibers. Serial cross-sections from $\mathrm{SM}$ muscles were incubated for $60 \mathrm{~min}$ at $37^{\circ} \mathrm{C}$ in $\mathrm{SDH}$ incubation solution $(0.1 \%$ nitro blue tetrazolium in $0.1 \mathrm{M}$ phosphate buffer $[\mathrm{pH}$ 7.2-7.6] containing $0.1 \mathrm{M}$ sodium succinate) and then rinsed in distilled $\mathrm{H} 2 \mathrm{O}$ ( 3 changes $\mathrm{x} 1 \mathrm{~min}$ ). To remove unbound blue tetrazolium, the sections were incubated in 3 changes ( 1 min per change) of acetone in water solutions (30,60, and 90\% acetone) in first increasing and then decreasing order of acetone concentration. Sections were rinsed in distilled $\mathrm{H} 2 \mathrm{O}$ for 3 changes ( 1 min each), dehydrated in graded ethanol solutions (i.e., 70, 90, and 100\%), cleared in xylene, and finally mounted in permanent medium (Canada Balsam).

Fibre typing by myofibrillar actomyosin ATPase histochemistry: Two different procedures were used for staining myofibrillar actomyosin ATPase following the methods described by Brooke and Kaiser [18,19] and by Guth and Samaha [20,21].

Alkali preincubated myofibrillar ATPase activity: Sections were air dried for $10 \mathrm{~min}$ at room temperature and then fixed for $3 \mathrm{~min}$ in $5 \%(\mathrm{w} / \mathrm{v})$ formaldehyde in a solution of $200 \mathrm{mM}$ sodium cacodylate, $68 \mathrm{mM} \mathrm{CaCl} 2$ and $340 \mathrm{mM}$ sucrose (adjusted with $\mathrm{HCl}$ to $\mathrm{pH} 7.6$ before formaldehyde was added). After incubation in wash solution (100 mM Tris and $18 \mathrm{mM} \mathrm{CaCl}$; $\mathrm{pH} 7.8$ ), an alkaline pre-incubation step was performed by maintaining the sections in $200 \mathrm{mM} 2$-amino3-methyl-1 propanol ( $\mathrm{pH} 10.4$ ) for $15 \mathrm{~min}$ at room temperature. After two successive $1 \mathrm{~min}$ incubations in the wash solution, sections were incubated in ATP solution $(2.7 \mathrm{mM} \mathrm{ATP}, 90 \mathrm{mM} \mathrm{CaCl} 2,100 \mathrm{mM}$ sodium barbital $\mathrm{pH} 9.4$ ) for $45 \mathrm{~min}$ at $37^{\circ} \mathrm{C}$.
Acid preincubated myofibrillar ATPase activity [22]: Sections were air dried for $10 \mathrm{~min}$ at room temperature and incubated in 100 $\mathrm{mM}$ sodium acetate ( $\mathrm{pH} 4.35$ ) for $10 \mathrm{~min}$ a room temperature. Sections were then washed ( 2 changes $\mathrm{x} 1 \mathrm{~min}$ each) in $18 \mathrm{mM} \mathrm{CaCl} 2$ and 100 $\mathrm{mM}$ Tris $\mathrm{HCl}$ ( $\mathrm{pH}$ 7.8) before incubation in the ATP solution (together with the serial sections undergoing the Alkali Preincubated Myofibrillar ATPase Activity technique). After washing in 2 changes (30 sec per change) of distilled $\mathrm{H} 2 \mathrm{O}$, sections were incubated for $5 \mathrm{~min}$ in $2 \%(\mathrm{w} / \mathrm{v})$ $\mathrm{CoCl} 2$, washed (2 changes $\mathrm{x} 30 \mathrm{sec}$ each) in distilled $\mathrm{H} 2 \mathrm{O}$, incubated for $5 \mathrm{~min}$ in $2 \%(\mathrm{v} / \mathrm{v})(\mathrm{NH} 4) 2 \mathrm{~S}$ in water, and then washed in distilled $\mathrm{H} 2 \mathrm{O}$ ( 2 changes $\mathrm{x} 30 \mathrm{sec}$ each). Finally, the sections were dehydrated in graded ethanol solutions (i.e., 70-90-100\%), cleared in xylene, and mounted in permanent medium (Canada Balsam).

Images were acquired using a Zeiss microscope connected to a Leica DC $300 \mathrm{~F}$ camera, under the same conditions that were used to photograph a reference ruler. The minimum transverse diameter of each muscle fiber was measured against the reference ruler. Morphometric analyses were performed with Scion Image for Windows version Beta 4.0.2 (2000 Scion Corporation, Frederick, MD, USA), free software downloaded from the web site: www.scioncorp.com.

\section{Results}

Size and fiber type composition of normal and UMN paraplegic muscle fibers before and after two years of FES training

Generally, in UMN (spastic) paraplegia human muscles reach soon and maintain a stable atrophy (Table 1 and [4]). Equally clear is the fact that there is a substantial increase of the relative content of the fast type 2B fibers in the MT and LT SCI (Tables 2 and 3). Whether this is the results of muscle fiber transformation due to SCI-induced muscle disuse and unloading or the loss of slow type 1 and 2A muscle fiber types is still debated.

Table 1: Diameter of normal and UMN paralyzed human muscle fibers Pre and Post 2 years of FES training

\begin{tabular}{|c|c|c|c|}
\hline & \multicolumn{3}{|c|}{$(\boldsymbol{\mu m}+/-\mathbf{S D})$} \\
\hline & Type 2B & Type 2A & Type 1 \\
\hline Normal muscle & $54,00+/-14,58$ & $43,91+/-13,88$ & $45,79+/-13,56$ \\
\hline PRE-FES & $44,17+/-4,88$ & $42,81+/-4,33$ & $41,42+/-4,28$ \\
\hline POST-FES & $60,53+/-3,44$ & not present & $42,29+/-8,97$ \\
\hline
\end{tabular}

Table 2: Percentage of fiber types in normal and UMN paralyzed human muscles

\begin{tabular}{|c|c|c|c|}
\hline & Type 2B & Type 2A & Type 1 \\
\hline & & $(\%)$ & 40 \\
\hline Normal muscle & 49 & 10 & 20 \\
\hline PRE-FES & 68 & 11 & 15 \\
\hline POST-FES & 85 & 0 & (\%) \\
\hline
\end{tabular}

Table 3: Percentage of fiber types in UMN paralyzed human muscles in MT and LT SCI

\begin{tabular}{|c|c|c|c|c|}
\hline & $\begin{array}{c}\text { From SCI } \\
\text { (Years) }\end{array}$ & Type 2B & Type 2A & Type 1 \\
\hline & & \multicolumn{3}{|c|}{ (\%) } \\
\hline Normal muscle & & 49 & 10 & 40 \\
\hline PRE-FES & $<5$ & 59 & 15 & 25 \\
\hline & $<5$ & 76 & 0 & 24 \\
\hline POST-FES & $>5$ & 80 & 4 & 15 \\
\hline & $>5$ & 91 & 0 & 9 \\
\hline
\end{tabular}




\section{SDH staining}

$\mathrm{SDH}$ is an oxidative enzyme localized in the mitochondria. The rodents type 1 fibers that have an oxidative metabolism stain darker than the type 2 fibers that have prevalently a glycolytic metabolism. These differences are less pronounced in human adult muscle. Nonetheless, the stain intensity of this mithochondrial enzyme decreases substantially in UMN paraplegic patient muscles (results not shown), suggesting a transition of the muscle fibers properties from those of the oxidative to those of the glycolytic muscle fibers.

\section{Myosin ATPase, pH 4.35}

Type 1 fibers stain dark, type 2A stain light, while the type 2B fibers are unstained. Decrease of the slow type of myosin is evident in UMN paraplegic muscles at mid-term, while it almost disappeared in the long-term UMN muscles, that are prevalently composed of fast type 2B muscle fibers.

\section{Myosin ATPase, pH 9.4}

After incubation at $\mathrm{pH}$ 9.4, myosin enzymatic activity of the fast 2B fiber type is relatively stable, whereas the slow myosin of Type 1 fiber is labile. Thus, the fast fibers stain dark, while oxidative fiber types stain intermediate (Type $2 \mathrm{~A}$ ) or very light (Type 1). These features allow to identify and to determine size and relative content of the 3 types of muscle fibers present in human Quadriceps m. (Tables 1 and 2 , respectively). In normal muscle, the fast type $2 \mathrm{~B}$ muscle fibers have a larger size (around $55 \mu \mathrm{m}$ of muscle fiber diamenter), while the oxidative muscle fibers (Types) $2 \mathrm{~A}$ and 1 have around $45 \mu \mathrm{m}$ of muscle fiber diamenter. Pooling all MT and LT SCI samples all the three types of muscle fibers decrease in diameter, while only the type $2 \mathrm{~B}$ muscle fibers increase in diameter after two years of FES. On the other hand, Post-FES muscle fibers generally increase of about $50 \%$ in size.

The possible transformation of oxidative $2 \mathrm{~A}$ muscle fibers to fast glycolytic muscle fibers is strongly suggested when the percentual content of the three different fiber types was determined, Table 2 shows that in the pooled results the percentual content increase from the normal value of $50 \%$ to $70 \%$ in UMN SCI biopsies before FES training and to $85 \%$ after two years of FES, mainly at the expense of the $2 \mathrm{~A}$ fiber types that are absent in this group of muscle biopsies. This trend is confirmed and more evident comparing the separated groups of midterm versus long-term UMN SCI muscle biopsies before and after 2 years of FES.

On the other hand, some muscle biopsies contain variable amount of lower motorneuron-denervated muscle fibers (that, is severely atrophic muscle fibers positive with the anti-NCAM [4].

\section{Discussion}

Complete spinal cord injury results often in a significant loss of muscle mass, or atrophy, in the affected areas of the body, the severity and extent of which depends on the level of lesion and on the survival of the motor neurons. Muscle atrophy has been studied in SCI patients from a variety of points of view. However, most studies in literature are focused on the early post-injury phase and did not follow the progression of atrophy that occurs in the long run. In the last twenty years some of us have extensively studied long-term atrophy progression in lower motor neuron lesion (flaccid) patients and the perspectives of training these very difficult cases with a purpose-developed FES training (Vienna FES strategy for denervated degenerating muscles) [23-25]. We demonstrated that: 1. human skeletal muscles survive permanent denervation longer (years) than generally accepted; 2 . FES started within the first year post-SCI provides the best results, but recovery of muscle mass and contractile function occur also in mid(3 years) and long-term (up to 6 years) subjects, if purpose developed protocols, electrodes and stimulator (now commercially available) are used [26-36].

Over the years, the benefit of the use of functional electrical stimulation (FES) to restore movement of the limbs of paralyzed patients has been largely discussed. For this reason information on the long-term progression of atrophy would be actually extremely important for the treatment of patients since it could give important clues to physiotherapist on how and when starting FES rehabilitation procedures and when the results will be poor or very poor. To date, however, not much is known about the long-term progression of muscle atrophy in upper motor neuron lesion (or spastic) patients. Indeed, in 2008 we published the first and only study reporting results of UMN spastic paraplegia up to twenty years from SCI [4]. In that study we investigated the long-term progression of atrophy in spastic patients using a multidisciplinary approach that compared a midterm group to a long-term group of patients, suffering with complete UMN lesion of the spinal cord (T3-T11), enrolled in a 2-year FES rehabilitation program. Those results confirmed that the complete UMN SCI paraplegics loss $50 \%$ of muscle mass during the first few (3 to 6) months but indicated very little progression of the muscle atrophy long-term (at least up to 20 years post injury), providing information that is of significant importance for the rehabilitation of long-term spastic patients. Furthermore, in the last 5 years we studied also elderly persons either performing high level amateur and competitive sports in their seventies or sedentary old septuagenarians before and after 3 months of FES training [37-45]. In all these cases we added our evidence to an extensive literature [46], demonstrating the negative effects of poor physical activity and the trophic recovery after an increased level of voluntary $[47,48]$ and/or FES-induced muscle contractile activity maintained for weeks, months or years [36-46].

Here we added further evidence that the stable atrophy of long-term $\mathrm{UMN}$ spastic paraplegia is accompanied by changes in the population of unloaded muscle fibers that explain, together with the ultrastructural modification we previously described [4], the poor or very poor fatigue resistance of these heavily unloaded skeletal muscles. We show here once again that FES training may reverse the atrophy process, though the amount of contractile activity inducible in clinical settings do not allow to reach the level needed to substantially increase the oxidative metabolism and thus endurance of paretic muscles. Nonetheless, other positive effects of the Vienna FES training is a beneficial hyperaemia of the stimulated muscles and of the skin with aesthetic modification of the legs and a valuable anti-decubitus ulcer effect $[24,25]$.

\section{Conclusions}

The analyses of type of fibers in muscles of UMN paraplegic patient before and after two-years of FES training demonstrate a remarkable and significant size increase, restricted to fast type muscle fibers, that increases in percentage, possibly as the result of muscle fiber transformation related to the dramatic decrease of load that is determined by paraplegia and a wheel-chair life-style.

Indeed, there is a decrease of oxidative muscle fibers, both the slow type 1 muscle fiber up to the absence of $2 \mathrm{~A}$ fiber type in POST-training patients. An increase in relative content of the type $2 \mathrm{~B}$ fibers is evident and progresses with time of SCI. The diameter of the slow type 1 muscle fibers slightly decreasew with UMN, but do not change during SCI time progression or after FES-training. 
Our conclusion is that muscle fibers adapt to unloading and to the decrease of contractile activity with fiber-type transformations. However, patent degeneration of the muscle tissue, as in the case of permanent long-term lower motor neuron denervation, was never observed. Furthermore, the fact that extent of training-induced results do not decreased with time from UMN SCI, is a strong evidence that there are no upper-time limits to begin FES.

\section{Conflicts of interest}

The authors declare none conflict of interest regarding the publication of this paper.

\section{Funding statement}

This work was supported by the Austrian Research Promotion Agency, Federal Ministry for Transport, Innovation and Technology (bmvit) and the Ludwig Boltzmann Society.

\section{Acknowledgments}

UC thanks for support A\&C M-C Foundation for Translational Myology, Padova, Italy.

\section{References}

1. Graupe D (2002) An overview of the state of the art of noninvasive FES for independent ambulation by thoracic level paraplegics. Neurol Res 24: 431-442. [Crossref]

2. Kern H, McKay WB, Dimitrijevic MM, Dimitrijevic MR (2005) Motor control in the human spinal cord and the repair of cord function. Curr Pharm Des 11: 1429-1439. [Crossref]

3. Lieber RL, Steinman S, Barash IA, Chambers H (2004) Structural and functional changes in spastic skeletal muscle. Muscle Nerve 29: 615-627. [Crossref]

4. Kern H, Hofer C, Mödlin M, Mayr W, Vindigni V, et al. (2008) Stable muscle atrophy in long-term paraplegics with complete upper motor neuron lesion from 3- to 20-year SCI. Spinal Cord 46: 293-304. [Crossref]

5. Esquenazi A, Talaty M, Packel A, Saulino M (2012) The ReWalk powered exoskeleton to restore ambulatory function to individuals with thoracic-level motor-complete spinal cord injury. Am J Phys Med Rehabil. 91:911-21.

6. Lotta S, Scelsi R, Alfonsi E, Saitta A, Nicolotti D, et al. (1991) Morphometric and neurophysiological analysis of skeletal muscle in paraplegic patients with traumatic cord lesion. Paraplegia 29: 247-252. [Crossref]

7. Scelsi R (2001) Skeletal muscle pathology after spinal cord injury. Our 20-year experience and results on skeletal muscle changes in paraplegics, related to functional rehabilitation. Basic Appl Myol 11: 75-86.

8. Gorgey SA and Dudley GA (2007) Skeletal muscle atrophy and increased intramuscular fat after incomplete spinal cord injury. Spinal Cord 45:304-309. [Crossref]

9. Taylor PN, Ewins DJ, Fox B, Grundy D, Swain ID (1993) Limb blood flow, cardiac output and quadriceps muscle bulk following spinal cord injury and the effect of training for the Odstock functional electrical stimulation standing system. Paraplegia 31:303-310. [Crossref]

10. Giangregorio LM, Webber CE, Phillips SM, Hicks AL, Craven BC, et al. (2006) Can body weight supported treadmill training increase bone mass and reverse muscle atrophy in individuals with chronic incomplete spinal cord injury? Appl Physiol Nutr Metab. 31:283-291. [Crossref]

11. Andersen JL, Mohr T Biering-Sørensen F, Galbo H, Kjaer M (1996) Myosin heavy chain isoform transformation in single fibers from $\mathrm{m}$. vastus lateralis in spinal cord injured individuals: effects of long-term functional electrical stimulation (FES). Pflugers Arch 431:513-518. [Crossref]

12. Castro MJ, Apple DF Jr, Staron RS, Campos GE, Dudley GA (1999) Influence of complete spinal cord injury on skeletal muscle within 6 mo of injury. J Appl Physiol (1985) 86: 350-358. [Crossref]

13. Crameri RM, Weston AR, Rutkowski S, Middleton JW, Davis GM, et al. (2000) Effects of electrical stimulation leg training during the acute phase of spinal cord injury: a pilot study. Eur J Appl Physiol 83: 409-415. [Crossref]
14. Adams MM, Ditor DS, Tarnopolsky MA, Phillips SM, McCartney N, et al. (2006) The effect of body weight-supported treadmill training on muscle morphology in an individual with chronic, motor-complete spinal cord injury: A case study. J Spinal Cord Med 29:167-171.

15. Mohr T, Andersen JL, Biering-Sørensen F, Galbo H, Bangsbo J, et al. (1997) Longterm adaptation to electrically induced cycle training in severe spinal cord injured individuals. Spinal Cord 35: 1-16. [Crossref]

16. Kern H, Boncompagni S, Rossini K, Mayr W, Fanò G,. Zanin ME, et al. (2004) Longterm denervation in humans causes degeneration of both contractile and excitationcontraction coupling apparatus that can be reversed by functional electrical stimulation (FES). A role for myofiber regeneration? J Neuropath Exp Neurol 63:919-931.

17. Carraro U, Rossini K, Mayr W, Kern H, et al (2005) Muscle fiber regeneration in human permanent lower motoneuron denervation: relevance to safety and effectiveness of FES-training, which induces muscle recovery in SCI subjects. Artif Organs 29:187191. [Crossref]

18. Brooke MH, Kaiser KK. J (1969) Some comments on the histochemical caracterization of muscle adenosin triphosphatase. Histochem Cytochem 17:431-2.

19. Brooke MH, Kaiser KK (1969) Muscle fiber types: How many and what kind? Arch Neurol 1970 23; 369-79.Guth L, Samaha FJ. Qualitative differences between actomyosin ATPase of slow and fast mammalian muscles Exp Neurol 25:139-52.

20. Guth L, Samaha FJ (1970) Procedure for the histochemical demonstration of actomyosin ATPase. Exp Neurol 28: 365-367. [Crossref]

21. Hämäläinen N, Pette D (1993) The histochemical profiles of fast fiber types IIB, IID and IIA in skeletal muscles of mouse, rat, and rabbit. J Histochem Cytochem 41: 733743. [Crossref]

22. Kern H, Hofer C, Loefler S, Zampieri S, Gargiulo P, et al. (2017) Atrophy, ultrastructural disorders, severe atrophy and degeneration of denervated human muscle in $\mathrm{SCI}$ and Aging. Implications for their recovery by Functional Electrical Stimulation, updated 2017. Neurol Res. 39:660-666. [Crossref]

23. Albertin G, Kern H, Hofer C, Guidolin D, Porzionato A, et al. (2018) Two years of Functional Electrical Stimulation by large surface electrodes for denervated muscles improve skin epidermis in SCI. Eur J Transl Myol. 28:7373. [Crossref]

24. Albertin G, Hofer C, Zampieri S, Vogelauer M, Löfler S, et al. (2018) In complete SCI patients, long-term functional electrical stimulation of permanent denervated muscles increases epidermis thickness. Neurol Res 40:277-282. [Crossref]

25. Carraro U, Kern H (2016) Severely atrophic human muscle fibers with nuclea misplacement survive many years of permanent denervation. Eur J Transl Myol. 26:76-80. [Crossref]

26. Kern H, Carraro U (2014) Home-based functional electrical stimulation (h-b FES) for long-term denervated human muscle: history, basics, results and perspectives of the Vienna rehabilitation strategy. Eur J Transl Myol. 24:27-40. [Crossref]

27. Kern H, Rossini K, Carraro U, Mayr W, Vogelauer M, et al. (2005) Muscle biopsies show that FES of denervated muscles reverses human muscle degeneration from permanent spinal motoneuron lesion. J Rehabil Res Dev 42: 43-53. [Crossref]

28. Kern H (1995) Funktionelle Elektrostimulation Paraplegischer Patienten [Functiona electrostimulation of paraplegic patients]. ÖZPM, Österreichische Zeitschrift für Physikalische Medizin. 5:1-75.

29. Kern H, Carraro U, Adami N, et al. (2010) One year of home-based functional electrica stimulation (FES) in complete lower motor neuron paraplegia: recovery of tetanic contractility drives the structural improvements of denervated muscle. Neurol Res. 32:5-12. [Crossref]

30. Kern H, Carraro U, Adami N, et al. (2010) Home-based functional electrical stimulation rescues permanently denervated muscles in paraplegic patients with complete lower motor neuron lesion. Neurorehabil Neural Repair 24:709-721. [Crossref]

31. Boncompagni S, Kern H, Rossini K, et al. (2007) Structural differentiation of skeletal muscle fibers in the absence of innervation in humans. Proc Natl Acad Sci USA. 104:19339-19344. [Crossref]

32. Gargiulo P, Reynisson PJ, Helgason B, Kern H, Mayr W, et al. (2011) Muscle, tendons, and bone: structural changes during denervation and FES treatment. Neurol Res 33: 750-758. [Crossref]

33. Edmunds KJ, Gíslason MK, Arnadottir ID, et al. (2016) Quantitative computed tomography and image analysis for advanced muscle assessment. Eur J Transl Myol 26:6015.

34. Available at: https://www.schuhfried.com/umbraco/Surface/AuthenticationSurface/ Login?returnUrl $=\% 2$ Fportal 
35. Tezze C, Romanello V, Desbats MA, Fadini GP, Albiero M, et al. (2017) Age-Associated Loss of OPA1 in Muscle Impacts Muscle Mass, Metabolic Homeostasis, Systemic Inflammation, and Epithelial Senescence. Cell Metab. 25:1374-1389.e6. [Crossref]

36. Zampieri S, Mammucari C, Romanello V, Barberi L, Pietrangelo L, et al. (2016) Physical exercise in aging human skeletal muscle increases mitochondrial calcium uniporter expression levels and affects mitochondria dynamics. Physiol Rep. 4(24). pii: e13005. [Crossref]

37. Carraro U, Kern H, Gava P, Hofer C, et al. (2017) Recovery from muscle weakness by exercise and FES: lessons from Masters, active or sedentary seniors and $\mathrm{SCI}$ patients. Aging Clin Exp Res 29: 579-590. [Crossref]

38. Zampieri S, Mosole S, Löfler S, Fruhmann H, Burggraf S, et al. (2015) Physical Exercise in Aging: Nine Weeks of Leg Press or Electrical Stimulation Training in 70 Years Old Sedentary Elderly People. Eur J Transl Myol 25: 237-242. [Crossref]

39. Carraro U, Kern H, Gava P, Hofer C, Loefler S, et al. (2015) Biology of Muscle Atrophy and of its Recovery by FES in Aging and Mobility Impairments: Roots and By-Products. Eur J Transl Myol 25: 221-230. [Crossref]

40. Barber L, Scicchitano BM, Musaro A (2015) Molecular and Cellular Mechanisms of Muscle Aging and Sarcopenia and Effects of Electrical Stimulation in Seniors. Eur J Transl Myol 25: 231-236. [Crossref]

41. Zampieri S, Pietrangelo L, Loefler S, Fruhmann H, Vogelauer M, et al. (2015) Lifelong physical exercise delays age-associated skeletal muscle decline. J Gerontol A Biol Sci Med Sci. 70:163-73. [Crossref]
42. Kern H, Barberi L, Löfler S, Sbardella S, Burggraf S, et al. (2014) Electrical stimulation counteracts muscle decline in seniors. Front Aging Neurosci. 6:189. [Crossref]

43. Mosole S, Carraro U, Kern H, Loefler S, Fruhmann H, et al. (2014) Long-term highlevel exercise promotes muscle reinnervation with age. J Neuropathol Exp Neurol. 73:284-294. [Crossref]

44. Sajer S (2017) Mobility disorders and pain, interrelations that need new research concepts and advanced clinical commitments. Eur J Transl Myol 27: 7179. [Crossref]

45. Paillard T (2018) Muscle plasticity of aged subjects in response to electrical stimulation training and inversion and/or limitation of the sarcopenic process. Ageing Res Rev 46: 1-13. [Crossref]

46. Carraro U, Karma Gava K, Baba A, Piccione F, Marcante A (2016) Fighting muscle weakness in advanced aging by takehome strategies: Safe anti-aging full-body in-bed gym and functional electrical stimulation (FES) for mobility compromised elderly people. Biol Eng Med, 1:1-4.

47. Carraro U, Gava K, Musumeci A, Baba A, Piccione F, (2018) Safe Antiaging Full-Body In-Bed Gym and FES for Lazy Persons: Home In-Bed Exercises for Fighting Muscle Weakness in Advanced Age. In: Rehabilitation Medicine for Elderly Patients, Masiero S, Carraro U, Eds., pag. 43-52.

48. Carraro U, Gava K, Baba A, Marcante A, Piccione F To contrast and reverse skeletal muscle atrophy by Full-Body In-Bed Gym, a mandatory life-style for older olds and borderline mobility impaired persons. Springer-Nature Book: Muscle Atrophy, Junjie Xiao, Ed., in press.

Copyright: (C2018 Hofer C. This is an open-access article distributed under the terms of the Creative Commons Attribution License, which permits unrestricted use, distribution, and reproduction in any medium, provided the original author and source are credited. 